\title{
Deriving Historical Temperature and Precipitation Time Series For Alaska Climate Divisions Via Climatologically Aided Interpolation
}

Russell S. Vose, Mike Squires, Derek Arndt, Imke Durre, Chris Fenimore, Karin Gleason, Matthew J. Menne, James Partain, Claude N. Williams, Jr. NOAA National Centers for Environmental Information

Peter A. Bieniek

International Arctic Research Center, University of Alaska, Fairbanks

Richard L. Thoman

Alaska Region, NOAA National Weather Service

2017

Journal of Service Climatology

Volume 10, Number 1

A Refereed Journal of the American Association of State Climatologists

Corresponding Author: Russell S. Vose, National Centers for Environmental Information, 151 Patton Avenue, Asheville, NC 28801, +1 828271 4311, Russell.Vose@noaa.gov 


\begin{abstract}
This paper describes the construction of temperature and precipitation time series for climate divisions in Alaska for 1925-2015. Designed for NOAA climate monitoring applications, these new series build upon the divisional data of Bieniek et al. (2014) through the inclusion of additional observing stations, temperature bias adjustments, supplemental temperature elements, and enhanced computational techniques (i.e., climatologically aided interpolation). The new NOAA series are in general agreement with Bieniek et al. (2014), differences being attributable to the underlying methods used to compute divisional averages in each dataset. Trends in minimum temperature are significant in most divisions whereas trends in maximum temperature are generally not significant in the eastern third of the state. Likewise, the statewide rate of warming in minimum temperature $\left(0.158^{\circ} \mathrm{C} \mathrm{dec}^{-1}\right)$ is roughly $50 \%$ larger than that of maximum temperature $\left(0.101{ }^{\circ} \mathrm{C} \mathrm{dec}^{-1}\right)$. Trends in precipitation are not significant for most divisions or for the state as a whole.
\end{abstract}




\section{Introduction}

Monthly Climate Reports are a key component of operational climate monitoring by the National Oceanic and Atmospheric Administration (NOAA). These monthly reports discuss recent events and historical trends at both the national and state level, primarily for temperature and precipitation. Detailed summaries are also available for 344 climate divisions within the conterminous United States (Vose et al., 2014). Notably, climate divisions have not been widely employed for the nation's largest state - Alaska - despite its rapidly changing climate (Walsh et al., 2014) and its large geographic extent, which accounts for about $15 \%$ of the total U.S. land area. This is mainly attributable to the relative paucity of observing stations in many remote areas as well as the topographic complexity of the state itself. Recently, Bieniek et al. (2012) addressed this problem by employing a combination of in situ and AVHRR data to objectively delineate a new set of 13 climate divisions for Alaska. These new divisions were designed to represent zones of homogeneous climatic variability, and they generally depict spatially coherent trends in temperature and precipitation (Bieniek et al., 2014).

This paper describes the development of monthly time series for these new Alaska climate divisions for use in operational climate monitoring by NOAA. Divisional trends and extremes for 1925-2015 are also presented. The time series discussed here (termed nClimDiv) expand upon those originally presented in Bieniek et al. (2014) in three ways. First, the nClimDiv temperature series contain adjustments for historical changes in observing practice across the network. Second, the nClimDiv series represent actual temperature and precipitation values rather than departures from average. Third, the nClimDiv product suite includes maximum and minimum temperature series in addition to average temperature and precipitation series. 


\section{Station Data}

The new divisional time series were developed using data from several observing networks in Alaska, including the Cooperative Observer (COOP) program, the Automated Surface Observing System (ASOS), the Remote Automatic Weather Station (RAWS) network (temperature only), and the Snow Telemetry (SNOTEL) network (precipitation only). The Global Historical Climatology Network (GHCN) - Daily dataset (Menne et al., 2012) was the source of COOP, ASOS, and RAWS data whereas monthly SNOTEL data were acquired from the National Resources Conservation Service. A suite of quality assurance reviews were applied to the daily data (Durre et al., 2010); flagged values were set to missing prior to the computation of monthly means and totals, which subsequently were subjected to further temporal and spatial checks (Lawrimore et al., 2011). To be included in the computation of divisional series, a station was required to have 10 or more years of record.

Adjustments for historical changes in station location, observation time, and temperature instrumentation are not included in GHCN-Daily. Consequently, monthly adjustments were calculated for all temperature stations using the "pairwise” method of Menne and Williams (2009). This approach performs automated intercomparisons of temperature series to detect and adjust for historical changes in observing practice, including local trends arising from changes in siting conditions (Menne et al., 2010; Hausfather et al., 2013). The approach involves developing a matrix of pairwise difference series between all stations in a network, then evaluating each difference series for both documented and undocumented changes. The NOAA Historical Observing Metadata Repository was the source of station history information (i.e., documented changes) for COOP and ASOS sites; in contrast, no station histories were available for RAWS stations. 
The final station network is depicted in Figure 1. The network contains 241 temperature and 260 precipitation stations vs. 163 used in the divisional dataset of Bieniek et al. (2014). Station density is slightly greater in the Southeast Interior and Panhandle portions of the state while data gaps are evident along the North Slope, Northeast Interior, and Bristol Bay areas. The number of stations increases rapidly until the mid-1950s, and continues to grow gradually until the mid2000s, then decreases somewhat through 2015 (driven primarily by the decline in the number of COOP stations). Each climate division has at least one station at the start of the record (1925). Monthly means and totals are generally available in near-real-time (i.e., for last month) for about 80 stations, rising to about 100 given a two-month lag.

\section{Gridding Method}

Climate division values were computed by interpolating station data to a grid and then areaaveraging the grid-point estimates. Gridding was accomplished via climatologically aided interpolation, a technique that accounts for biases resulting from variations in station coverage and topography (Willmott and Robeson, 1995; Vose et al., 2014). This interpolation approach requires the availability of two grid types for each climatic element: grids of climate normals for each calendar month, and grids of climate anomalies for each year and month (i.e., from 1925 to present). The grids of climate normals depict fine-scale details using as many stations as possible while the grids of climate anomalies depict broad departures from average using only the stations in operation at that particular time. The final grid for each year and month is obtained by merging the grids of normals and anomalies.

The grids of climate normals were obtained from the PRISM Climate Group at Oregon State University (Daly et al., 2008). These grids were generated using the Parameter-elevation 
Relationships on Independent Slopes Model (PRISM), an interpolation method that explicitly accounts for elevation, terrain orientation, terrain profile, moisture regime, coastal proximity, inversion layers, and topographic position. The climatology represents the period 1971-2010, and it was derived using a spatially denser station network than is available in GHCN-Daily for that period. For consistency with NOAA's existing divisional products for the lower 48 states, the PRISM grids were resampled to a nominal latitude/longitude spacing of $5 \mathrm{~km}$ from their native higher resolution using a focal median technique (i.e., by finding the median within a search radius of four grid cells).

The grids of climate anomalies were created using a three-step process. The first step involved estimating climate normals for each station and month by finding the nearest grid cell in the high-resolution PRISM climatology, then assigning the grid-cell normals to the station. The next step entailed calculating a departure from average (i.e., a climate anomaly) for each station, year, and month. For temperature, each anomaly was computed by subtracting the station's calendar-month climate normal from its observed temperature in that year and month. For precipitation, each anomaly was calculated by dividing the station's observed total in that year and month by its calendar-month climate normal. The anomalies were then interpolated to the 5-km grid via the method of Willmott et al. (1985), which computes an estimate at each grid point using 15-25 neighboring stations whose weights are proportionate to their distance to the grid point. To improve predictive skill, the approach uses spherical coordinates rather than Cartesian two-space, accounts for the directional isolation of stations relative to grid points, and extrapolates beyond the range of the data to a limited extent. For additional information on the interpolation of anomalies, see Vose et al. (2014). 
The final grid for each year and month was created by merging the grids of normals and anomalies. The final grid for maximum and minimum temperature in each year and month was derived by adding the grid of anomalies for that year and month to the grid of normals for that calendar month. The final average temperature grid in each year and month was defined as the average of the maximum and minimum grids. The final precipitation grid for each year and month was calculated by multiplying the grid of anomalies for that year and month by the grid of normals for the calendar month.

\section{Interpolation Error}

A three-step cross-validation exercise was employed to estimate interpolation error for each element. The initial step required the computation of a climate anomaly residual - that is, the mean absolute difference between the anomaly at a given station in a given month and the anomaly estimated using neighboring stations (i.e., by interpolating their values to the target station using inverse-distance weighting). The next step involved interpolating the monthly residuals to the $5 \mathrm{~km}$ grid via inverse-distance weighting and then computing the annual average of the monthly gridded residuals. The final step involved area-averaging the gridded residuals into climate division values.

Figure 2 presents area-averaged cross-validation values at the divisional level over the period 1925-2015. For maximum temperature, errors decrease more rapidly before 1940 than thereafter, averaging about $1.0^{\circ} \mathrm{C}$ at present for all divisions. A similar decrease is evident for minimum temperature, though present-day errors are slightly higher (about $1.5{ }^{\circ} \mathrm{C}$ ), and interdivisional variability is larger throughout the record. For precipitation, errors exhibit only a subtle decrease through time, leveling off at about $40 \mathrm{~mm}$ for divisions along the Gulf of Alaska and 
roughly $20 \mathrm{~mm}$ for drier divisions to the north. Starting in 1998, there is a slight increase in precipitation errors for some divisions along the Gulf of Alaska; this is attributable to the deployment of about 10 new ASOS stations in fairly wet locations in the Kenai Peninsula and the Alaska Panhandle.

\section{Temperature Trends}

Figure 3 depicts annual temperature trends for 1925-2015 at the divisional level (trends were computed via least-squares regression, significance being assessed with the Student's t-test under an assumption of independent/identically distributed residuals). Warming is evident in almost every division and is largest in western/central Alaska. Trends in minimum temperature are statistically significant (at the 0.10 level) for all divisions except the Northern Panhandle; in contrast, trends in maximum temperature are generally not significant in the eastern third of the state (e.g., divisions in the eastern interior and the panhandle). For most divisions, trends in minimum temperature are about $0.050{ }^{\circ} \mathrm{C} \mathrm{dec}^{-1}$ larger than trends in maximum temperature. Similarly, the statewide rate of warming in minimum temperature $\left(0.158^{\circ} \mathrm{C} \mathrm{dec}^{-1}\right)$ is roughly $50 \%$ larger than that of maximum temperature $\left(0.101^{\circ} \mathrm{C} \mathrm{dec}{ }^{-1}\right)$. Both statewide trends are statistically significant.

For average temperature, nClimDiv exhibits trends that are in general agreement with Bieniek et al. (2014). For example, the respective statewide trends are 0.101 and $0.088{ }^{\circ} \mathrm{C} \mathrm{dec}^{-1}$ through 2012, the last year of the Bieniek et al. (2014) analysis. Both datasets also depict widespread warming throughout Alaska except for small divisions in the panhandle (Figure 3). However, trend magnitudes differ slightly at the divisional level, leading to somewhat divergent patterns of warming. Specifically, the largest increases in nClimDiv are in central Alaska whereas 
Bieniek et al. (2014) has the greatest warming in the northeast (and greater spatial variability overall). This pattern difference likely stems from the methods used to compute divisional averages in each dataset. In the case of Bieniek et al. (2014), each divisional value is the arithmetic mean of station observations in that division. That method works well with sufficiently dense networks but may lead to biases when a division is spatially undersampled and topographic variability is large (Guttman and Quayle, 1996; Vose et al., 2014), which is the case in northeastern Alaska, an area roughly the size of Montana. In particular, only 5 stations are in the Northeast Interior division and just 10 are in the North Slope division (all but 1 of which are on the coast); furthermore, each division has only 1 station with more than 50 years of data. In contrast, nClimDiv is based on station anomalies interpolated from a specified minimum number of sites regardless of their divisional affiliation, a computational practice that generally reduces networkinduced variability (Willmott and Robeson, 1995).

From the perspective of annual climate extremes (Figure 4), there is reasonably good agreement between the datasets during their period of overlap (1925-2012). For example, both datasets exhibit very similar temperature patterns in 1956, the coldest year on record in nClimDiv. In fact, the only apparent difference in that year is the Northeast Interior division, which was record-cold in Bieniek et al. (2014) versus $3^{\text {rd }}$ coldest in nClimDiv. The datasets diverge a bit more in 2002, the warmest year in nClimDiv during the overlap period. The most striking difference is the North Slope division, which is record-warm in nClimDiv but only above average in Bieniek et al. (2014). Smaller differences are also apparent for the large West Coast and Central Interior divisions, which are record-warm in nClimDiv versus $3^{\text {rd }}$ and $4^{\text {th }}$ warmest, respectively, in Bieniek et al. (2014). 
Other metrics confirm the general similarity between the datasets at the climate division level. For instance, the mean absolute difference between each nClimDiv monthly divisional anomaly series and its counterpart in Bieniek et al. (2014) is always less than $0.5{ }^{\circ} \mathrm{C}$. Likewise, Spearman rank correlations on the monthly anomaly series exceed 0.9 for all divisions except the sparsely sampled North Slope (0.89).

\section{6. $\quad$ Precipitation Trends}

Figure 5 depicts annual average precipitation trends at the climate division level. The datasets exhibit somewhat similar patterns of change since 1925, such as a small increase in the West Coast, a small decrease in the Central Interior, no change in the North Slope, and a large decrease in the Northeast Gulf. Notably, however, only about 25\% of the divisional trends are actually significant at the 0.10 level, and only the Northeast Gulf division has a statistically significant trend in both datasets. Not surprisingly, statewide precipitation trends are also not significant in either dataset.

Other metrics highlight noteworthy discrepancies between the datasets. For instance, the largest mean absolute differences are for divisions with few stations - i.e., the North Slope, Northeast Interior, and Northern Panhandle, all averaging about 10\% of normal. These divisions also have the lowest rank correlations $(<0.75)$. As with temperature, these large differences are likely attributable to the method used in Bieniek et al. (2014), which can sometimes underperform when a large area has a sparse station network. An illustrative example in this regard is 1928 (Figure 6), the wettest year for both datasets; notably, the North Slope and Southeast Interior divisions are above normal in nClimDiv but much-below normal in Bieniek et al. (2014), a discrepancy that likely stems from having less than three stations per division that year. 


\section{Summary}

This paper described the construction of time series for Alaska climate divisions for 19252015. Building on the foundational work of Bieniek et al. (2014), nClimDiv includes maximum and minimum temperature series as well as actual divisional temperature and precipitation estimates (vs. departures from average). From a methods perspective, nClimDiv was developed using additional observing stations, temperature bias adjustments, and enhanced computational techniques (i.e., climatologically aided interpolation). Cross-validation indicated that present-day area-average interpolation errors were roughly $1.0^{\circ} \mathrm{C}$ for maximum temperature, $1.5{ }^{\circ} \mathrm{C}$ for minimum temperature, $40 \mathrm{~mm}$ for precipitation in divisions along the Gulf of Alaska, and $20 \mathrm{~mm}$

for drier divisions to the north. For 1925-2015, most divisions have significant increases in maximum and minimum temperature except for the eastern third of Alaska, where maximum temperatures have not increased significantly; divisional trends in precipitation are largely insignificant. Overall, there is good general agreement between nClimDiv and Bieniek et al. (2014). The nClimDiv dataset is freely available from the National Centers for Environmental Information (https://www.ncdc.noaa.gov/news/climate-division-data-now-available-alaska). 


\section{References}

Bieniek, P.A., J.E. Walsh, R.L. Thoman, and U.S. Bhatt, 2014: Using climate divisions to analyze variations and trends in Alaska temperature and precipitation. J. Climate, 27, 2800-2818, doi:10.1175/JCLI-D-13-003421.

Bieniek, P.A., U.M. Bhatt, R.L. Thoman, H. Angeloff, J. Partain, J. Papineau, F. Fritsch, E. Holloway, J.E. Walsh, C. Daly, M. Shulski, G. Hufford, D.F. hill, S. Calos, and R. Gens, 2012: Climate divisions for Alaska based on objective methods. J. Appl. Meteor. Climatol., 51, 12761289, doi:10.1175/JAMC-D-11-0168.1.

Daly, C., M. Halbleib, J.I. Smith, W.P. Gibson, M.K. Doggett, G.H. Taylor, J. Curtis, and P.P. Pasteris, 2008: Physiographically sensitive mapping of climatological temperature and precipitation across the conterminous United States. Int. J. Climatol., 28, 2031-2064.

Durre, I., M.J. Menne, B.E. Gleason, T.G. Houston, and R.S. Vose, 2010: Comprehensive automated quality assurance of daily surface observations. J. Appl. Meteor. Climatol. 49, 1615-1633, doi:10.1175/2010JAMC2375.1

Guttman, N. B. and R. G. Quayle, 1996: A historical perspective of U.S. climate divisions. Bull. Amer. Meteor. Soc., 77, 293-303. 
Hausfather, Z., M.J. Menne, C.N. Williams, Jr., T. Masters, R. Broberg, and D. Jones, 2013: Quantifying the impact of urbanization on U.S. Historical Climatology Network temperature records. J. Geophys. Res., 118, 481-494, doi:10.1029/2012JD018509.

Lawrimore, J., M. Menne, B. Gleason, C. Williams, Jr., D. Wuertz, R. Vose, and J. Rennie, 2011: An overview of the Global Historical Climatology Network monthly mean temperature dataset, version 3. J. Geophys. Res., 116, D19121, doi:10.1029/2011JD016187.

Menne, M.J., I. Durre, B.E. Gleason, T. Houston, and R.S. Vose, 2012: An overview of the Global Historical Climatology Network Daily dataset. J. Atmos. Oceanic Technol., 29, 897-910, doi:10.1175/JETCH-D-11-00103.1

Menne, M.J., C.N. Williams, Jr., and M.A. Palecki, 2010: On the reliability of the U.S. surface temperature record. J. Geophys. Res., 115, D11108, doi:10.1029/2009JD013094.

Menne, M.J. and C.N. Williams, Jr., 2009: Homogenization of temperature series via pairwise comparisons. J. Climate, 22, 1700-1717.

Vose, R.S., S. Applequist, M. Squires, I. Durre, M.J. Menne, C.N. Williams, Jr., C. Fenimore, K. Gleason, and D. Arndt, 2014: Improved historical temperature and precipitation time series for U.S. climate divisions. Journal of Applied Meteorology and Climatology, 53,1232-1251, doi:10.1175/JAMC-D-13-0248.1. 
Walsh, J., D. Wuebbles, K. Hayhoe, J. Kossin, K. Kunkel, G. Stephens, P. Thorne, R. Vose, M. Wehner, J. Willis, D. Anderson, S. Doney, R. Feely, P. Hennon, V. Kharin, T. Knutson, F. Landerer, T. Lenton, J. Kennedy, and R. Somerville. 2014. Chapter 2: Our Changing Climate. In Climate Change Impacts in the United States: The Third National Climate Assessment, J. M. Melillo, Terese (T.C.) Richmond, and G. W. Yohe, editors., U.S. Global Change Research Program, 19-67. doi:10.7930/J0KW5CXT.

Willmott, C.J., C.M. Rowe, and W.D. Philpot, 1985: Small-scale climate maps: A sensitivity analysis of some common assumptions associated with grid-point interpolation and contouring. Am. Cartographer, 12, 5-16.

Willmott, C.J. and S.M. Robeson, 1995: Climatologically aided interpolation (CAI) of terrestrial air temperature. Int. J. Climatol., 15, 221-229. 

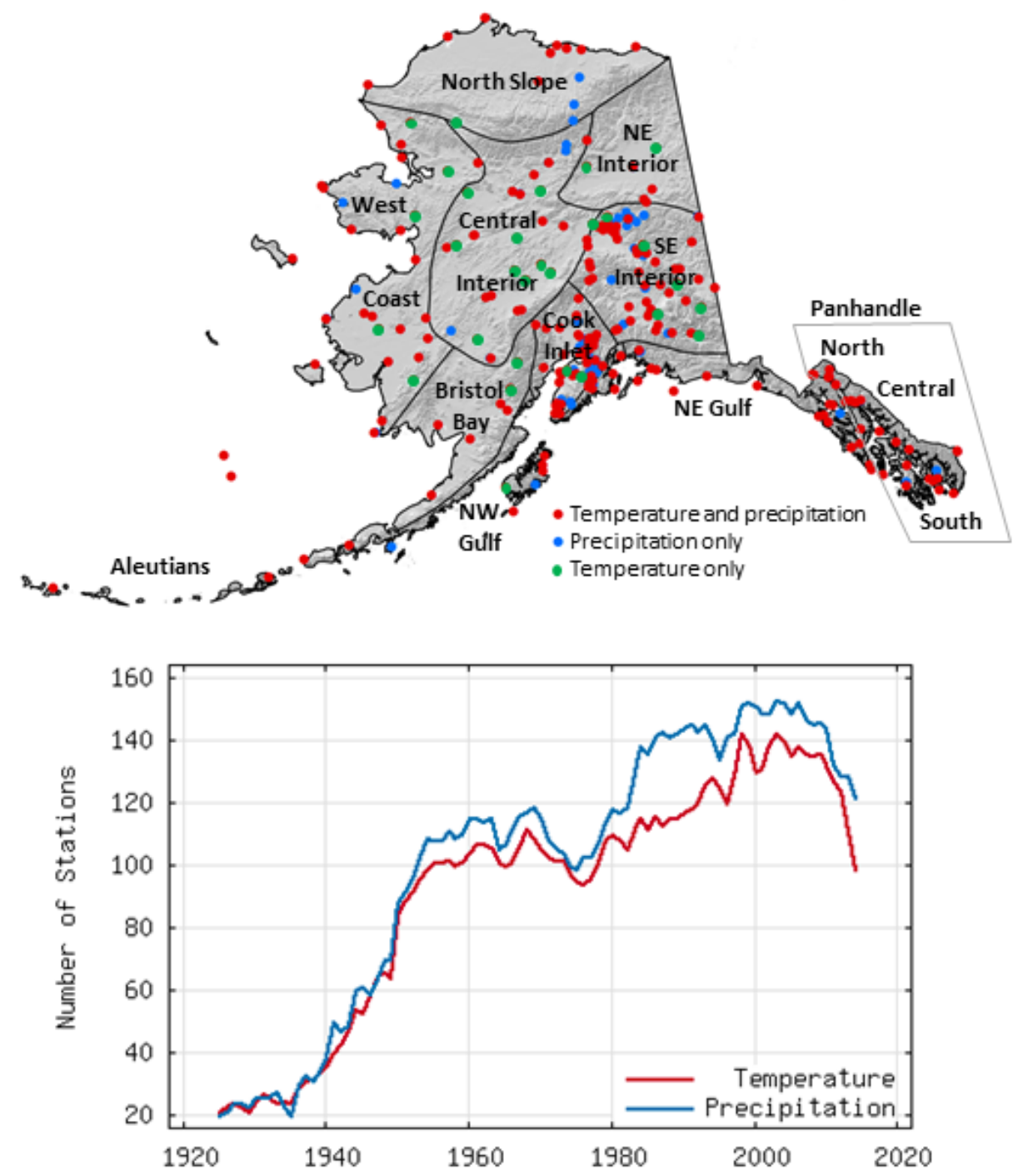

Figure 1. Map of station locations and divisional boundaries (top) and plot of the number of stations through time (bottom). 

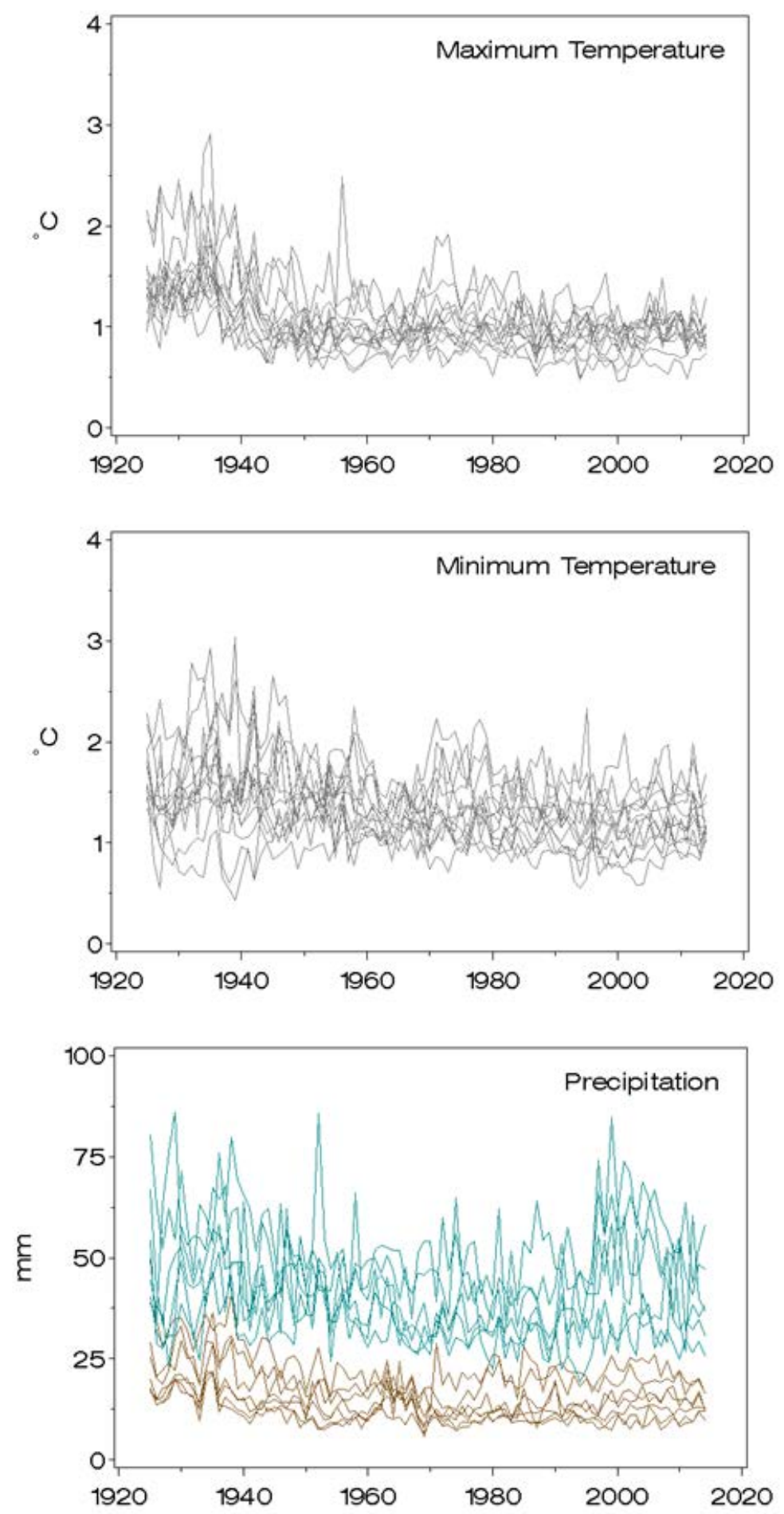

Figure 2. Plot of cross-validation errors through time for climate divisions. For maximum and minimum temperature, each division is plotted in grey. For precipitation, divisions in the north are plotted in brown while divisions along the southern coast and panhandle are plotted in green. 

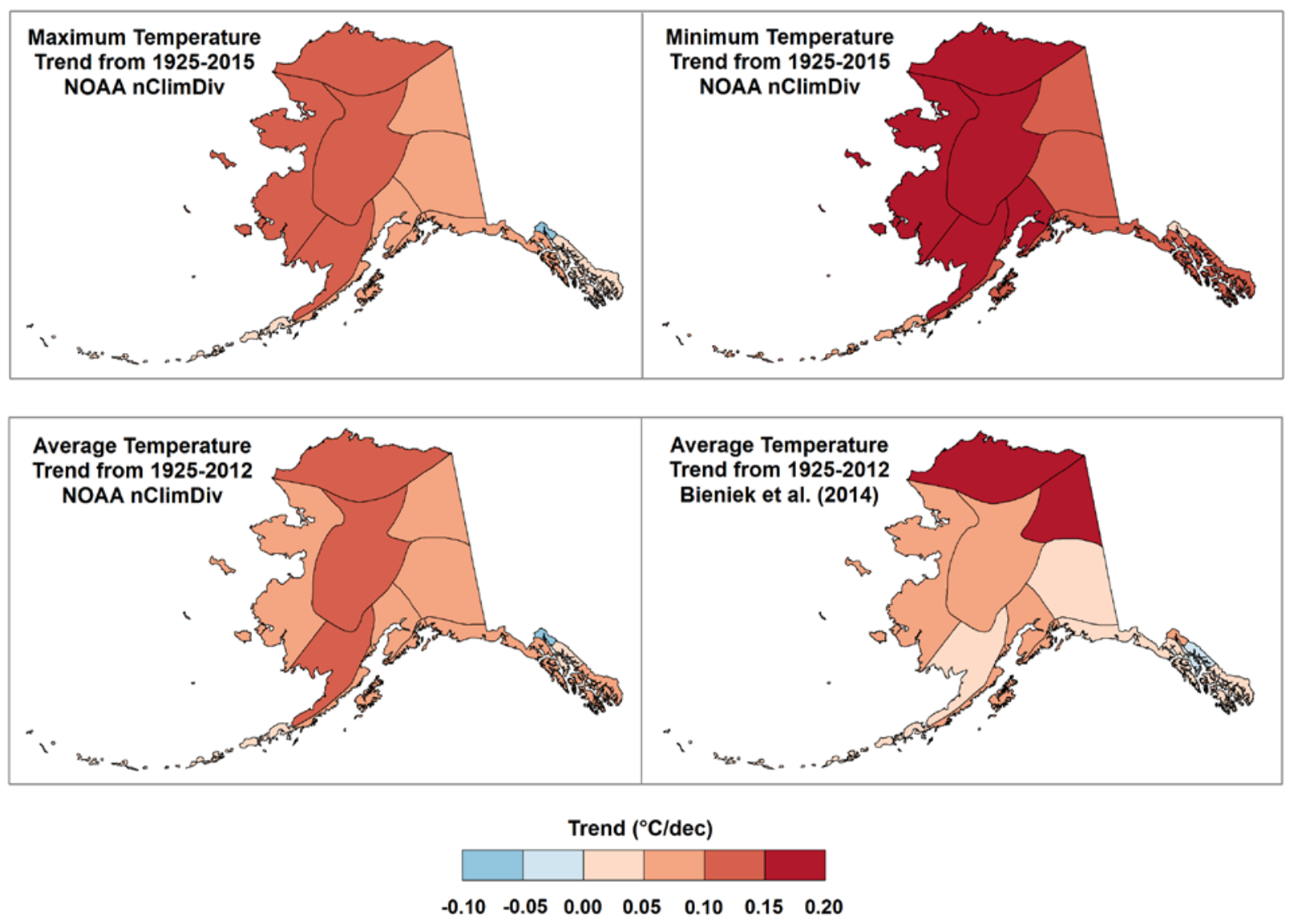

Figure 3. Annual temperature trends for climate divisions. 

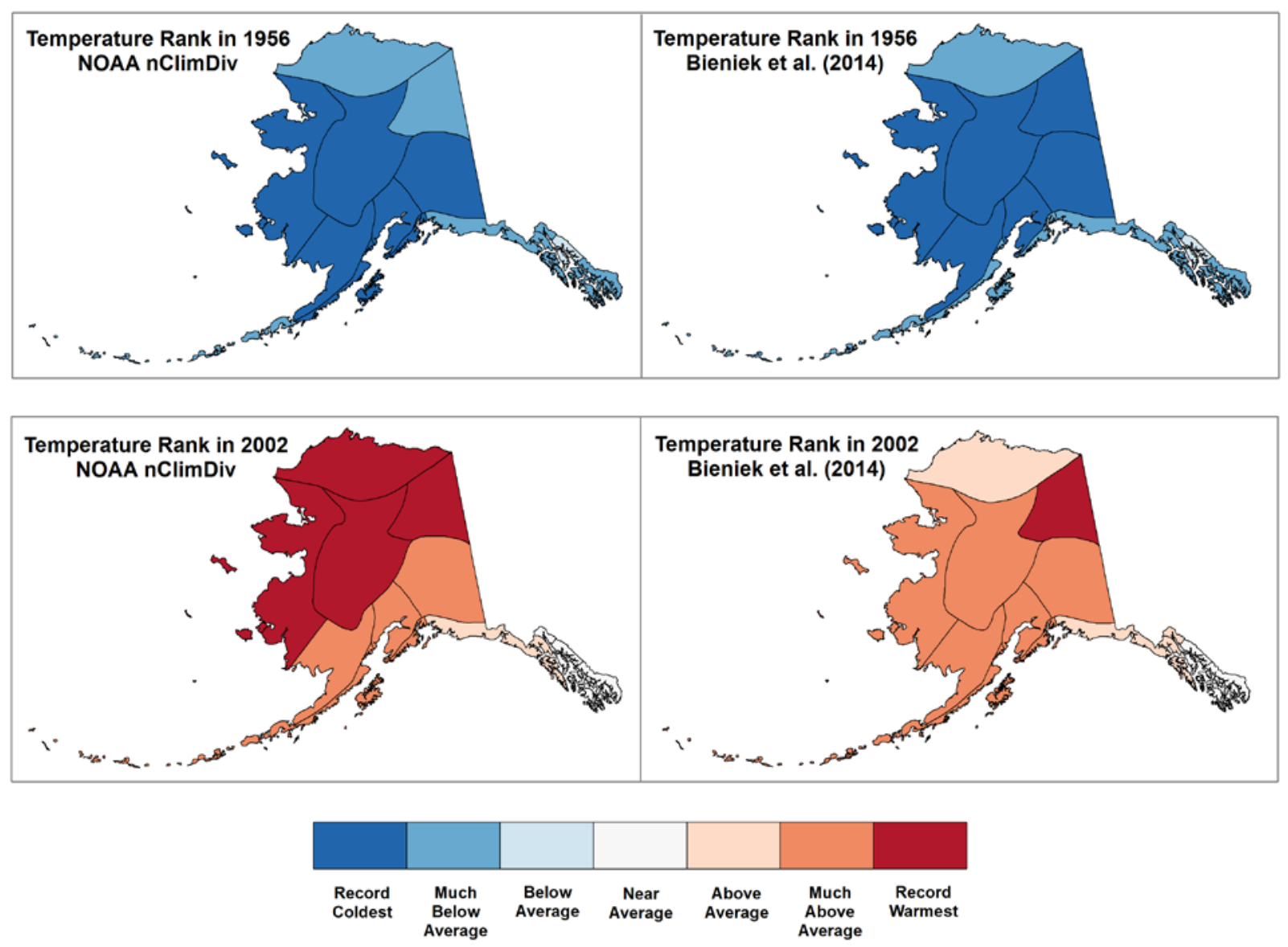

Figure 4. Annual temperature ranks for climate divisions in 1956 and 2002 (the coldest and warmest years in nClimDiv). 

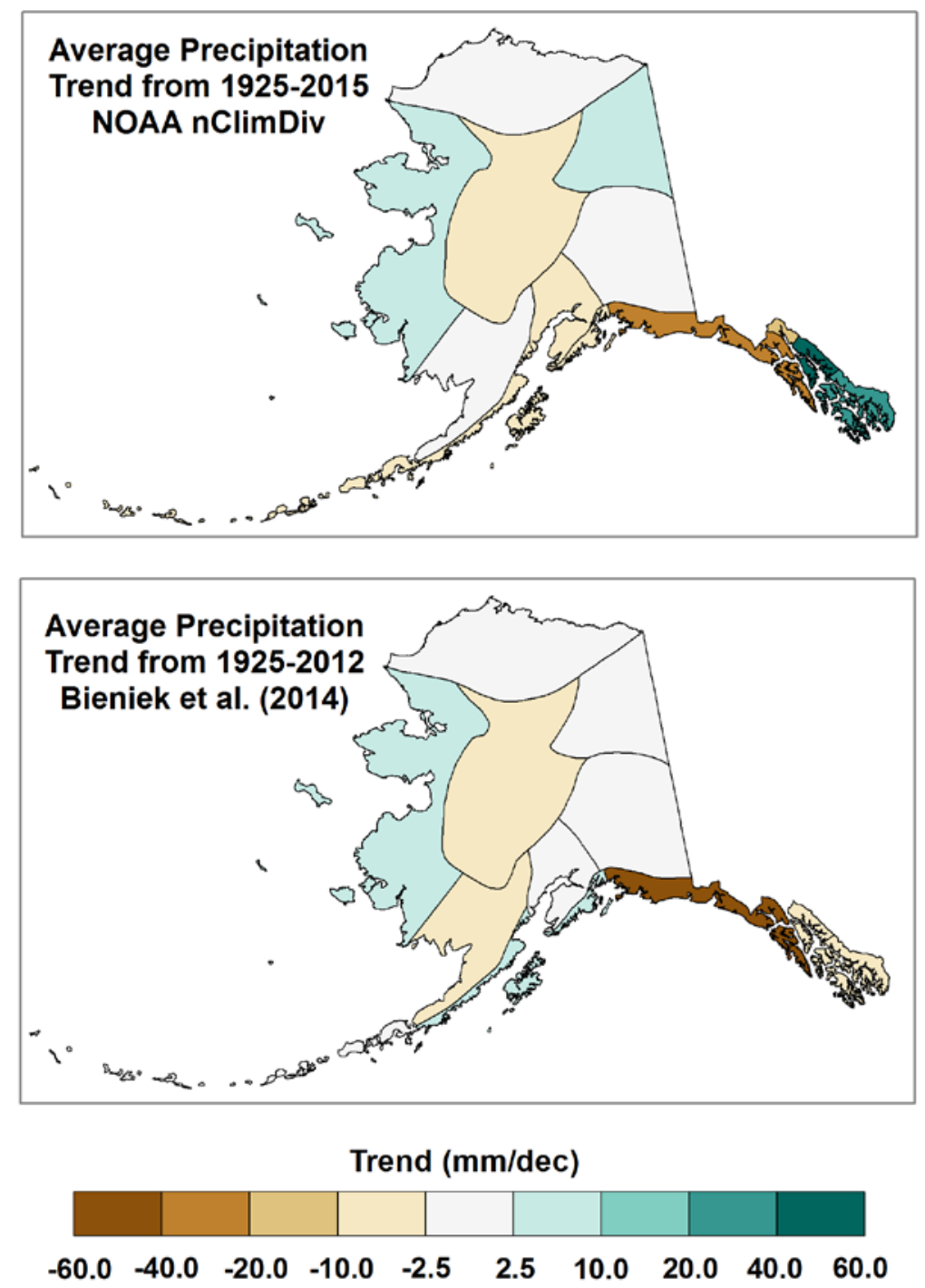

Figure 5. Annual precipitation trends for climate divisions. 


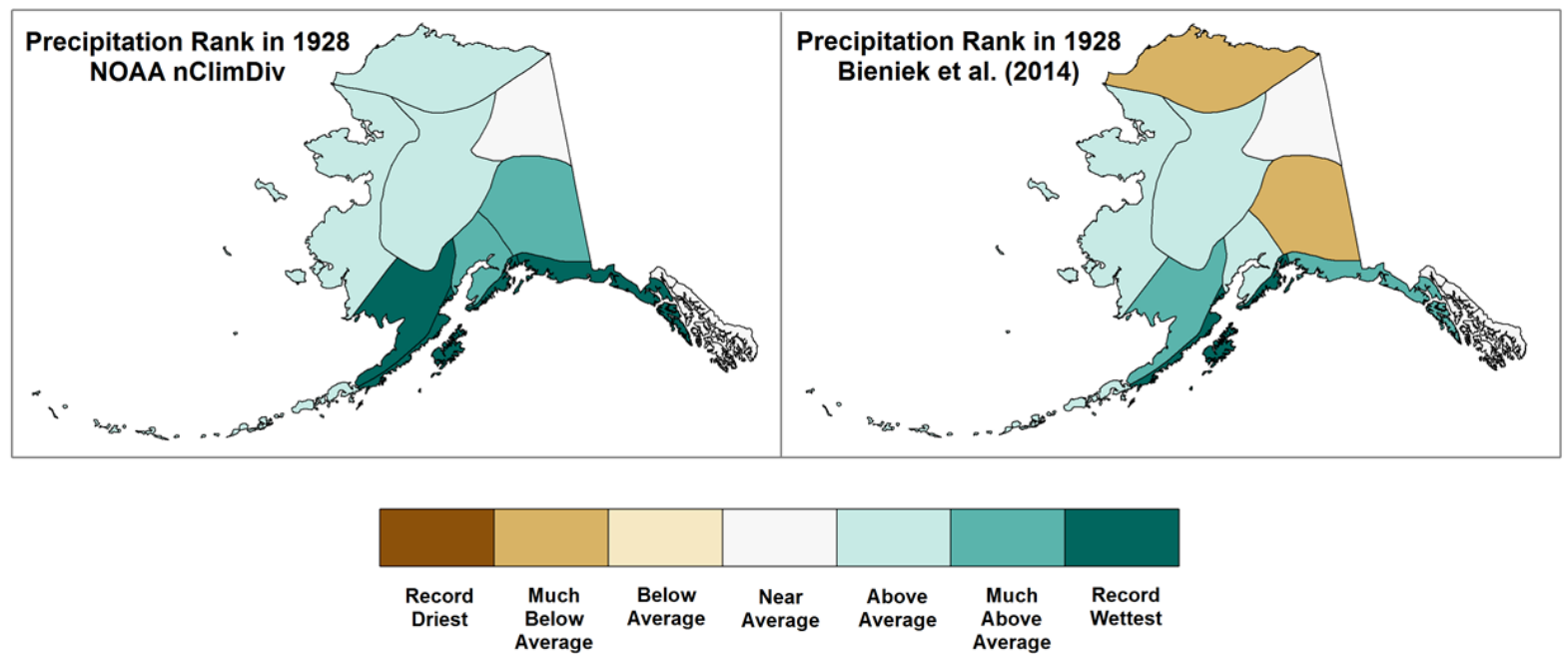

Figure 6. Annual precipitation ranks for climate divisions in 1928 (the wettest year on record in both datasets). 